\title{
ANALYSIS OF AN AXIALLY AND LATERALLY LOADED TAPERED PILE IN SAND
}

\author{
A. Siva RedDY* and G. Ramasamy*
}

\begin{abstract}
In the soil surrounding a laterally loaded pile, there are two zones; the top plastic zone where the soil yields once the ultimate resistance is reached and the bottom elastic zone where the soil reaction is proportional to pile deflection. In this paper, an analysis is presented for an axially and laterally loaded, uniformly tapering circular pile embedded in sand, taking into account the plastic behaviour of the soil near the ground surface. The differential equations governing the pile deflection at the top plastic zone and the bottom elastic zone are transformed to non-dimensional form and solutions are obtained. Free-free and fixed-free end conditions are considered. Top deflection coefficients and maximum moment coefficients are plotted against lateral load factor for different axial load factors and taper. For given axial and lateral loads, the top deflection and the maximum moment are found to increase with taper. The fixity at the top considerably reduces the deflection at the top. A numerical problem is worked out to illustrate the use of the plots to obtain the top deflection and the maximum moment.
\end{abstract}

Key words: analytical concept, deformation, horizontal load, pile, sand, subgrade reaction coefficient

IGC: $\quad$ E2

\section{INTRODUCTION}

Flexural analysis of piles is generally carried out on the basis of Winkler's hypothesis, according to which the reaction offered by the soil is linearly proportional to the deflection. This approach gives the top deflection of the pile as linearly proportional to the lateral load which does not agree well with the field observations. The discrepancy is attributed to the plastic behaviour of the soil near the ground surface. On the basis of the investigations, Kananyan (1968) has noted the existence of two zones in the soil surrounding the pile; the upper plastic zone and lower elastic zone. Analysis for laterally loaded uniform cross-section piles taking into account the plastic behaviour of the soil near ground surface has also been reported by Kananyan (1968), Siva Reddy and Valsangkar (1970) and Van Leyden (1971). However, field situations are many, where piles are required to resist both axial and lateral loads. Tapered piles are widely used in such cases. A realistic estimate of the pile deflection and maximum moment which are essential for the design could be done only if the analysis takes due care of the variation of the flexural rigidity of tapered piles, the plastic behaviour of the soil near

* Professor and Senior Research Fellow, respectively, Department of Civil Engineering, Indian Institute of Science, Bangalore-12, India.

Written discussions on this paper should be submitted before October 1, 1974 . 
ground surface and the axial load. Hence, in this paper, an analysis which takes care of the above factors is presented for a uniformly tapering circular pile embedded in sand and subjected to axial and lateral loads.

\section{LATERAL SOIL RESISTANCE}

There are a few methods suggested in literature to estimate the plastic resistance offered by the soil against pile deflection. Reese (1958) suggested that a triangular wedge of soil near the ground surface moves upwards when rupture takes place and obtained an expression for the plastic resistance that a saturated cohesive soil would exert against the pile. Broms (1964) assumed the plastic resistance offered by a cohesionless soil as equal to three times the Rankine's passive pressure. Herein, a wedge of soil as shown in Fig. 1 (as proposed by Luzan and reported by Kananyan, 1968) is assumed to flow outwards when ruptured. Assuming the rupture plane cdef to be straight and considering the equilibrium of the wedge under the forces

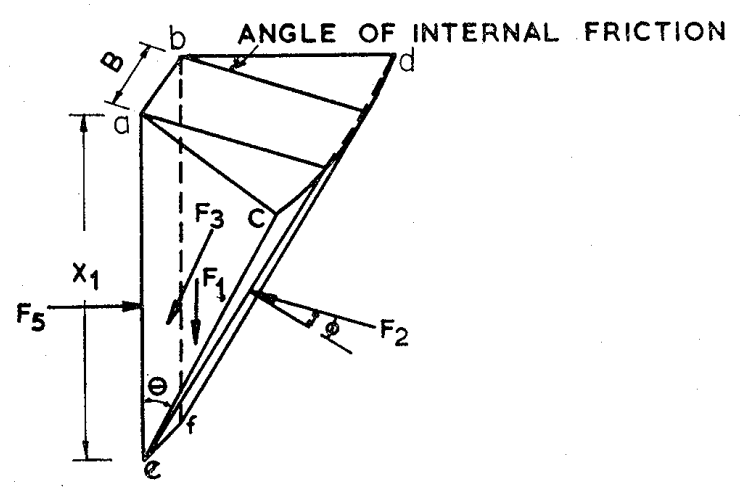

Fig. 1. Yielding wedge of the soil near ground surface

1) weight of the shearing soil mass $F_{1}$,

2) reaction $F_{2}$ inclined at an angle $\phi$ with the normal to the plane cdef,

3) shearing forces $F_{3}$ and $F_{4}$ on the planes ace and bdf, and

4) pile reaction $F_{5}$,

the ultimate soil resistance per unit length of the pile, put is obtained as

$$
p_{u t t}=t_{1} x+t_{2} x^{2}
$$

in which

$$
\begin{aligned}
t_{1} & =\gamma B \tan \theta \cot (\theta-\phi), \\
t_{2} & =\{\sin \theta+\cos \theta \cot (\theta-\phi)\} k_{0} \gamma \tan \theta \tan \phi+\gamma \tan ^{2} \theta \tan \phi \cot (\theta-\phi), \\
r & =\text { bulk unit weight of the soil, } \\
B & =\text { width of the pile, } \\
k_{0} & =\text { coefficient of earth pressure at rest, } \\
\phi & =\text { angle of internal friction of soil, } \\
\theta & =\text { angle made by the plane cdef with the vertical. }
\end{aligned}
$$

Values of $\theta$ for different values of $\phi$ are given by Kananyan (1968). The value of $B$ is taken as the diameter at the top of the pile since the small variation of the pile diameter over the depth of the plastic zone would not alter the values of plastic resistance significantly. 
The soil reaction at the bottom elastic zone is assumed to be proportional to the deflection. As suggested by Terzaghi (1955), for sands, the soil reaction per unit length of the pile, $p$ is given as

in which

$$
\begin{aligned}
p & =\frac{A \gamma}{1.35 B} B y \\
& =k y
\end{aligned}
$$

$k=$ the constant of horizontal subgrade reaction $=\frac{A r}{1.35}$,

$A=$ coefficient which depends on the relative density of sand, and $y=$ the pile deflection.

Terzaghi (1955) suggested values of $A$ that may be adopted for different relative densities of sand and the same is used for calculation of $k$.

\section{ANALYSIS}

Fig. 2a shows a circular tapered pile uniformly tapering from top diameter $D_{0}$ to diameter $C D_{0}$ at the bottom. The moment of inertia at depth $x$ from the ground level is given as

in which

$$
I(x)=I_{0}(1+b x)^{4}
$$

$$
\begin{aligned}
I_{0} & =\text { moment of inertia of the pile-cross section at the top, } \\
b & =(C-1) / L, \text { and } \\
L & =\text { length of pile. }
\end{aligned}
$$

The axial load decreases with depth due to the skin frictional resistance. The magnitude of the skin frictional resistance is dependent, among other factors, on the density of sand, the roughness of the pile surface, the amount of axial deformation and the taper of the pile. The too many factors which influence the skin frictional resistance put a limitation on the choice of an acceptable variation which will be suitable for varied soil and pile conditions. However, for mathematical simplicity, a parabolic variation of axial load (Fig. 2b) involving taper of the pile is assumed and is given by

$$
P(x)=P(1+b x)^{2}
$$

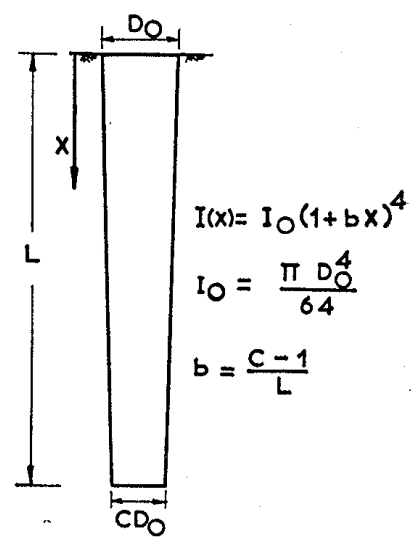

(a)

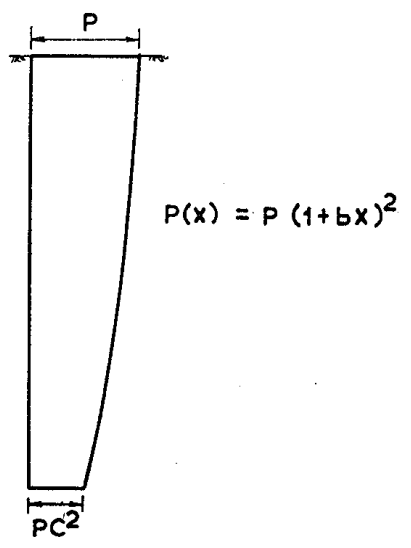

(b)

Fig. 2. Typical tapered pile and axial load distribution 
For $C=1$ (Uniform cross-section pile), Eq. (8a) reduces to

$$
P(x)=P
$$

which implies that the skin frictional resistance, though exists, is neglected for the case of uniform cross-section piles.

The differential equations governing the pile deflection at the top plastic and bottom elastic zones are given respectively as

$$
\frac{d^{2}}{d x^{2}}\left[E I_{0}(1+b x)^{4} \frac{d^{2} y}{d x^{2}}\right]+\frac{d}{d x}\left[P(1+b x)^{2} \frac{d y}{d x}\right]+t_{1} x+t_{2} x^{2}=0 \quad \text { for } 0 \leq x \leq x_{1}
$$

and

$$
\frac{d^{2}}{d x^{2}}\left[E I_{0}(1+b x)^{4} \frac{d^{2} y}{d x^{2}}\right]+\frac{d}{d x}\left[P(1+b x)^{2} \frac{d y}{d x}\right]+k x y=0 \quad \text { for } x_{1} \leq x \leq L
$$

in which

$$
\begin{aligned}
& E=\text { Young's modulus of elasticity of the pile material, } \\
& x_{1}=\text { depth of plastic zone. }
\end{aligned}
$$

Eqs. (9) and (10) are transformed to non-dimensional form using the following nondimensional parameters. Depth coefficient,

$$
z=\frac{x}{R},
$$

Maximum depth coefficient,

$$
z^{\prime}=\frac{L}{R},
$$

Non-dimensional depth of plastic zone,

$$
z_{1}=\frac{x_{1}}{R},
$$

Deflection coefficient,

$$
A_{y}=\frac{y E I_{0}}{t_{2} R^{6}},
$$

Moment coefficient,

$$
A_{M}=\frac{M}{t_{2} R^{4}},
$$

Axial load factor,

$$
U=\frac{P R^{2}}{E I_{0}},
$$

Plastic resistance coefficient,

$$
W=\frac{t_{1}}{t_{2} R}
$$

and Relative stiffness factor,

$$
R=\sqrt[5]{\frac{E I_{0}}{k}}
$$

in which

$$
M=\text { Bending moment. }
$$

The transformed non-dimensional equations corresponding to Eqs. (9) and (10) are, respectively, 


$$
\frac{d^{2}}{d z^{2}}\left[\left(1+d^{\prime} z\right)^{4} \frac{d^{2} A_{y}}{d z^{2}}\right]+U \frac{d}{d z}\left[\left(1+d^{\prime} z\right)^{2} \frac{d A_{y}}{d z}\right]+W z+z^{2}=0 \quad \text { for } 0 \leq z \leq z_{1}
$$

and $\frac{d^{2}}{d z^{2}}\left[\left(1+d^{\prime} z\right)^{4} \frac{d^{2} A_{y}}{d z^{2}}\right]+U \frac{d}{d z}\left[\left(1+d^{\prime} z\right)^{2} \frac{d A_{y}}{d z}\right]+z A_{y}=0 \quad$ for $z_{1} \leq z \leq z^{\prime}$

in which

$$
d^{\prime}=\frac{C-1}{z^{\prime}}
$$

\section{Solution of Eq. (19)}

Eq. (19) is a homogeneous linear differential equation and can be [reduced to a differential equation with constant coefficients using the known mathematical substitution, namely,

$$
\left(1+d^{\prime} z\right)=e^{v}
$$

Thus, Eq. (19) is reduced to the form,

$$
\frac{d^{4} A_{y}}{d v^{4}}+2 \frac{d^{3} A_{y}}{d v^{3}}+(\eta-1) \frac{d^{2} A_{y}}{d v^{2}}+(\eta-2) \frac{d A_{y}}{d v} \lambda_{1}+\lambda_{2} e^{v}+\lambda_{3} e^{2 v}=0
$$

in which

$$
\begin{aligned}
\eta & =\frac{U}{d^{\prime 2}}, \\
\lambda_{1} & =\frac{1}{d^{\prime 6}}-\frac{W}{d^{\prime 5}} \\
\lambda_{2} & =\frac{W}{d^{\prime 5}}-\frac{2}{d^{\prime 6}},
\end{aligned}
$$

and

$$
\lambda_{3}=1 / d^{\prime 6}
$$

Assuming the solution of Eq. (23) to be of the form,

$$
A_{y}=e^{\alpha v}
$$

the auxiliary equation is obtained as

The four roots of Eq. (29) are,

$$
\alpha^{4}+2 \alpha^{3}+(\eta-1) \alpha^{2}+(\eta-2) \alpha=0
$$

$$
\alpha_{1}=0, \alpha_{2}=-1, \alpha_{3}=-\frac{1}{2}+\sqrt{\frac{9}{4}-\eta}
$$

and

$$
\alpha_{4}=-\frac{1}{2}-\sqrt{\frac{9}{4}-\eta}
$$

Thus, the general solution of Eq. (23) may be written as

$$
A_{y 1}=C_{1}+C_{2} e^{-v}+C_{3} e^{\alpha_{3} v}+C_{4} e^{\alpha}{ }^{v}
$$

The particular integral for Eq. (23) is given as

$$
A_{y 2}=-\frac{\lambda_{1}}{(\eta-2)} v-\frac{\lambda_{2}}{2 \eta} e^{v}-\frac{\lambda_{3}}{(24+6 \eta)} e^{2 v}
$$

when $\eta=0$ (i.e. $U=0$ ),

$$
A_{y 2}=\frac{\lambda_{1}}{2} v-\frac{\lambda_{2}}{6} v e^{v}-\frac{\lambda_{3}}{24} e^{2 v}
$$


The complete solution for Eq. (23) is given by

$$
A_{y}=A_{y 1}+A_{y 2}
$$

Solution of Eq. (20)

Using Eq. (22), Eq. (20) is reauced to tne lorıı

$$
\frac{d^{4} A_{y}}{d v^{4}}+2 \frac{d^{3} A_{y}}{d v^{3}}+(\eta-1) \frac{d^{2} A_{y}}{d v^{2}}+(\eta-2) \frac{d A_{y}}{d v}+\frac{e^{v}-1}{d^{\prime 5}} A_{y}=0
$$

The solution of Eq. (35) is assumed in the form of a series as

$$
A_{y}=\sum_{n=0}^{\infty} a_{n} v^{n}
$$

Substituting Eq. (36) in Eq. (35) and equating the coefficients of each power to zero, the following relationships are obtained.

$$
a_{4}=\frac{-12 a_{3}-2(\eta-1) a_{2}-(\eta-2) a_{1}}{24}
$$

and

$$
a_{n}=\frac{\left[-2(n-1)(n-2)(n-3) a_{n-1}-(\eta-1)(n-2)(n-3) a_{n-2}-(\eta-2)(n-3) a_{n-3}-\lambda_{4}\right.}{\left.\times\left(\frac{a_{n-5}}{1 !}+\frac{a_{n-6}}{2 !}+\cdots\right)\right]}
$$

in which

$$
\lambda_{4}=1 / d^{\prime 5}
$$

and the solution is given by

$$
A_{y}=a_{0} f_{0}(v)+a_{1} f_{1}(v)+a_{2} f_{2}(v)+a_{3} f_{3}(v)
$$

in which

$$
\begin{aligned}
& f_{0}(v)=1-\frac{\lambda_{4}}{5 !} v^{5}+\frac{\lambda_{4}}{6 !} v^{6}-\frac{\lambda_{4}(4-\eta)}{7 !} v^{7}+\cdots \\
& f_{1}(v)=v-\frac{(\eta-2)}{4 !} v^{4}+\frac{2(\eta-2)}{5 !} v^{5}+\frac{\left(\eta^{2}-5 \eta+10\right)}{6 !} v^{6}+\cdots \\
& f_{2}(v)=v^{2}-\frac{2(\eta-1)}{4 !} v^{4}+\frac{2 \eta}{5 !} v^{5}+\frac{\left(2 \eta^{2}-8 \eta+2\right)}{6 !} v^{6}+\cdots
\end{aligned}
$$

and

$$
f_{3}(v)=v^{3}-\frac{1}{2} v^{4}+\frac{6(5-\eta)}{5 !} v^{5}+\frac{12 \eta}{6 !} v^{6}+\cdots
$$

The constants $C_{1}, C_{2}, C_{3}, C_{4}, a_{0}, a_{1}, a_{2}, a_{3}$ and the lateral load that brings a depth of soil $z_{1}$ into plastic zone are obtained using the continuity conditions between the plastic. and elastic zones and the boundary conditions. The continuity conditions for deflection, slope, bending moment, shear, and pressure are given respectively as

$$
\begin{aligned}
\left(A_{y}\right)_{u} & =\left(A_{y}\right)_{\imath} \\
\left(\frac{d A_{y}}{d v}\right)_{u} & =\left(\frac{d A_{y}}{d v}\right)_{l}
\end{aligned}
$$




$$
\begin{gathered}
\left(\frac{d^{2} A_{y}}{d v^{2}}-\frac{d A_{y}}{d v}\right)_{u}=\left(\frac{d^{2} A_{y}}{d v^{2}}-\frac{d A_{y}}{d v}\right)_{\imath} \\
{\left[d^{\prime 3} e^{v}\left(\frac{d^{3} A_{y}}{d v^{3}}+\frac{d^{2} A_{y}}{d v^{2}}-2 \frac{d A_{y}}{d v}\right)+U e^{v} d^{\prime} \frac{d A_{y}}{d v}\right]_{u}} \\
=\left[d^{\prime 3} e^{v}\left(\frac{d^{3} A_{y}}{d v^{3}}+\frac{d^{2} A_{y}}{d v^{2}}-2 \frac{d A_{y}}{d v}\right)+U e^{v} d^{\prime} \frac{d A_{y}}{d v}\right]_{l}
\end{gathered}
$$

and

$$
\left(\lambda_{1}+\lambda_{2} e^{v}+\lambda_{3} e^{2 v}\right)_{u}=\left(\frac{e^{v}-1}{d^{\prime 5}} A_{y}\right)_{\imath}
$$

The subscripts $u$ and $l$ refer to the interface as approached from the top plastic zone and bottom elastic zone, respectively.

The four boundary conditions for the free-free pile are that at $z=0$, moment is zero and shear force is the applied lateral load and at $z=z^{\prime}$, moment and shear force are zero. They are given respectively as at $z=0$,

$$
\begin{gathered}
\frac{d^{2} A_{y}}{d v^{2}}-\frac{d A_{y}}{d v}=0 \\
d^{\prime 3} e^{v}\left(\frac{d^{3} A_{y}}{d v^{3}}+\frac{d^{2} A_{y}}{d v^{2}}-2 \frac{d A_{y}}{d v}\right)+U e^{v} d^{\prime} \frac{d A_{y}}{d v}=A_{Q}
\end{gathered}
$$

at $z=z^{\prime}$,

$$
\frac{d^{2} A_{y}}{d v^{2}}-\frac{d A_{y}}{d v}=0
$$

and

in which

$$
d^{\prime 3} e^{v}\left(\frac{d^{3} A_{y}}{d v^{3}}+\frac{d^{2} A_{y}}{d v^{2}}-2 \frac{d A_{y}}{d v}\right)+U e^{v} d^{\prime} \frac{d A_{y}}{d v}=0
$$

$$
A_{Q}=\text { non-dimensional lateral load factor }=\frac{Q}{t_{2} R^{3}}
$$

For fixed-free pile, the slope $=0$ at $z=0$ i.e.

$$
\frac{d A_{y}}{d v}=0
$$

Other conditions are given by Eqs. (50), (51) and (52).

\section{RESULTS AND DISCUSSION}

For a range of values of $A_{Q}$, for which the soil near ground surface yields, the top deflection coefficients $A_{y 0}$ and maximum moment coefficients are plotted in Figs. 3 and 4 for free-free case and in Figs. 5 and 6 for fixed-free case for $W=0.25$ and $0.5, C=$ 1.0, 0.75 and 0.6 and for different axial load factors. The axial load factors are expressed in terms of $U_{c r}$, the buckling load for an end bearing free-free uniform crosssection pile embedded in a soil having constant coefficient of horizontal subgrade reaction. The value of $U_{c r}=0.9193$ as reported by Valsangkar (1969). The plots are for $z^{\prime}=4.0$ and may be used for $z^{\prime}>4$ as the error introduced is insignificant (Siva Reddy and Valsangkar, 1970). For any other intermediate values of $W, C$ and $U_{c r}$, top deflection coefficients and maximum moment coefficients may be interpolated from Figs. 3 to 6 . 

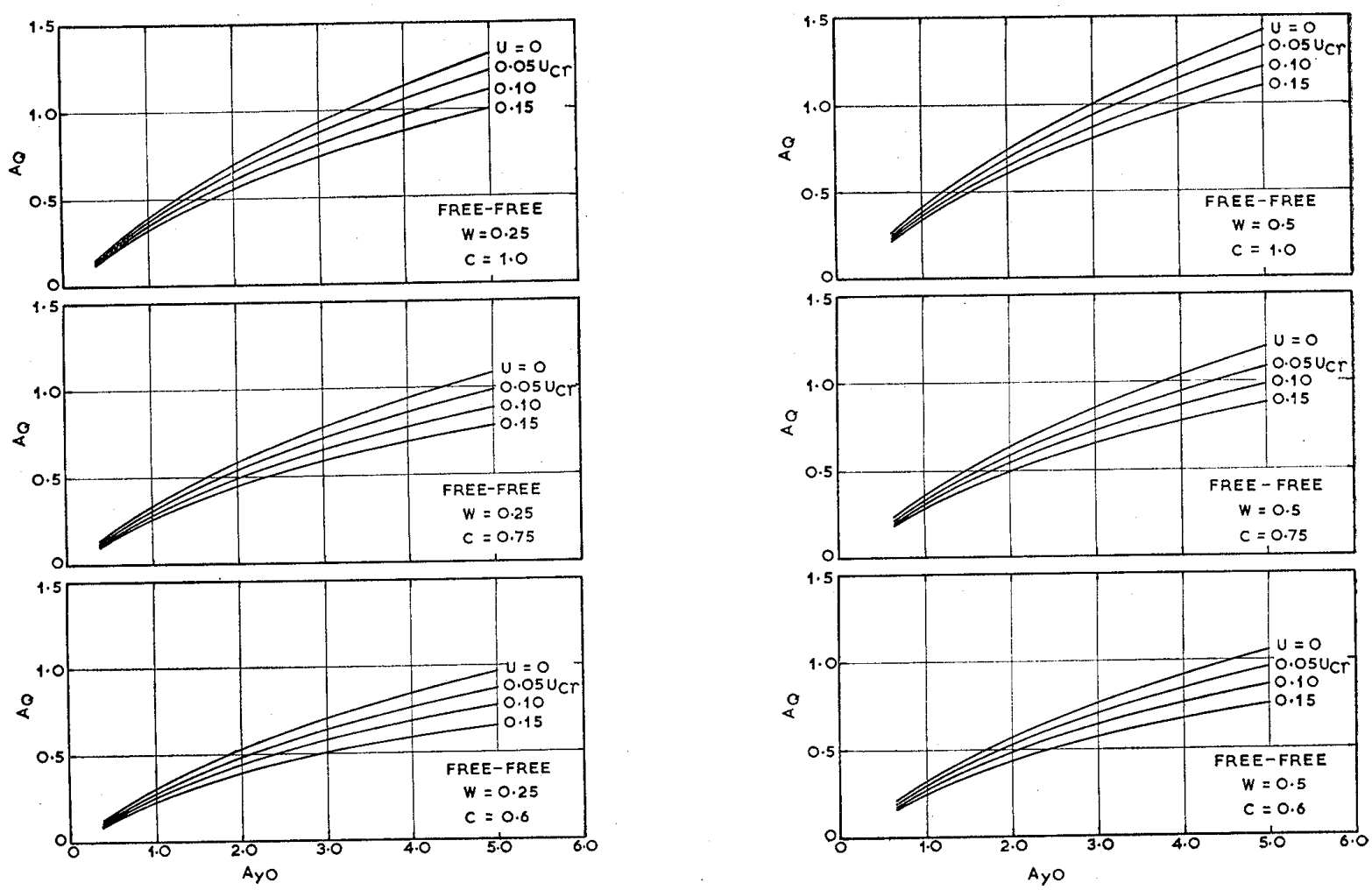

(a)

(b)

Fig. 3. $A_{Q}$ vs. $A_{y o}$ for free-free pile
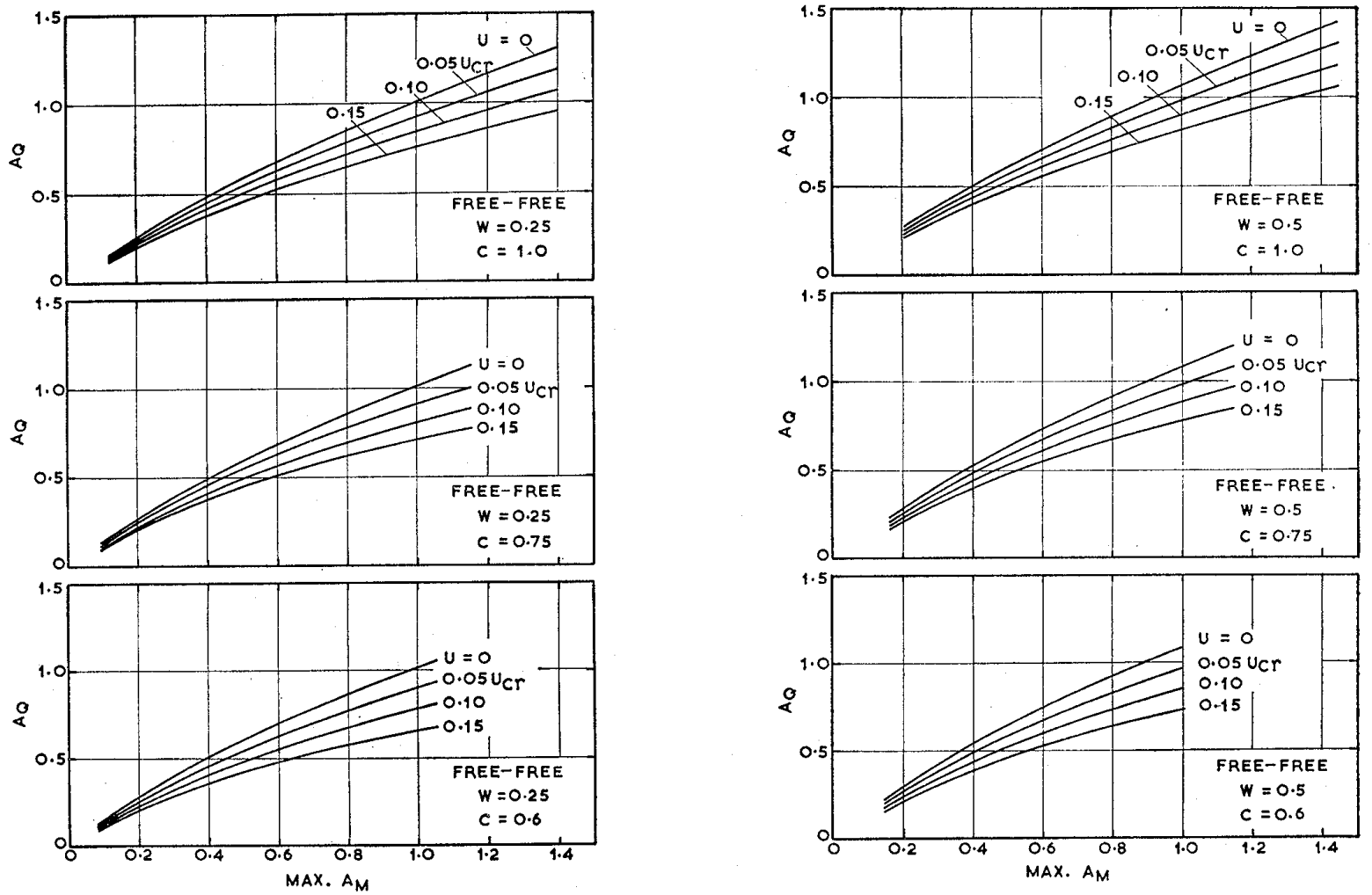

(a)

(b)

Fig. 4. $A_{Q}$ vs. Max. $A_{M}$ for free-free pile 

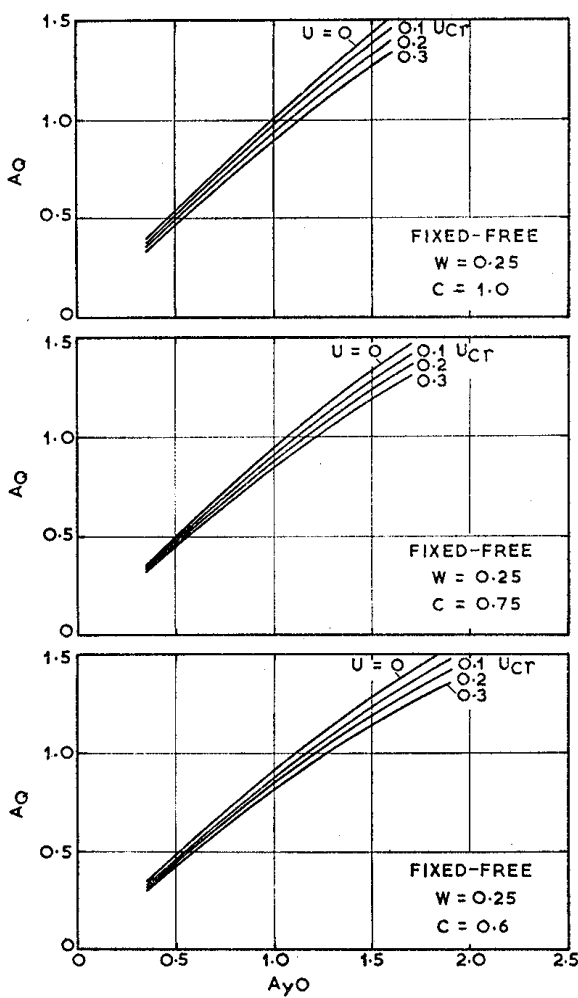

(a)
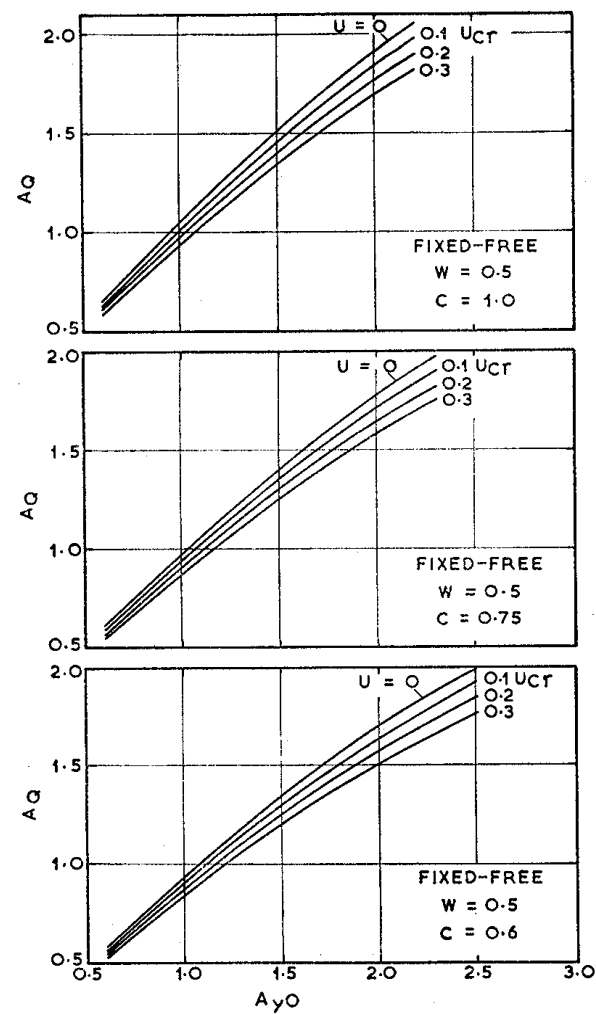

(b)

Fig. 5. $A_{Q}$ vs. $A_{y o}$ for fixed-free pile
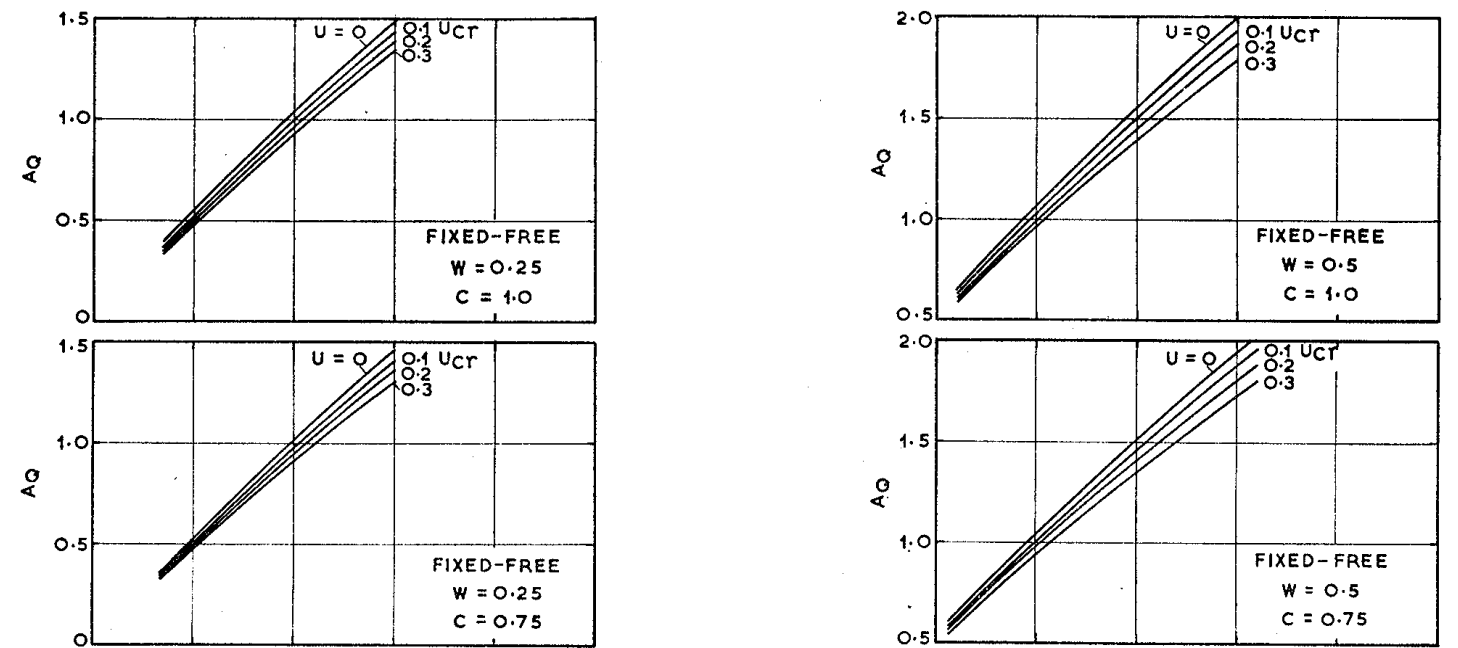

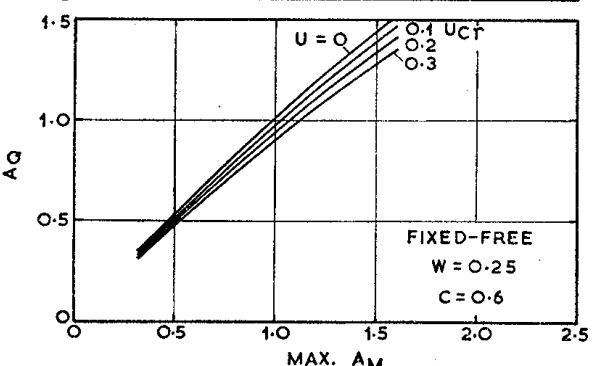

(a)

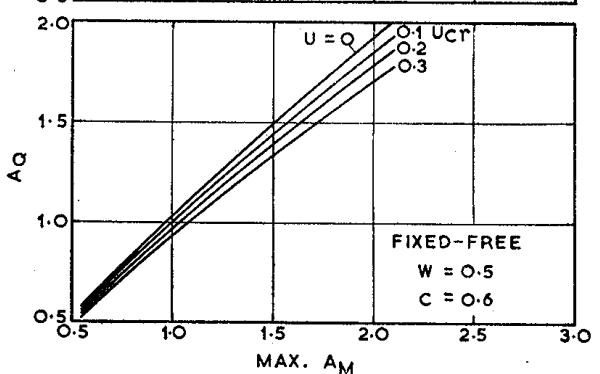

(b)

Fig. 6. $A_{Q}$ vs. Max. $A_{M}$ for fixed-free pile 
Figs. 3 to 6 show that the top deflection and maximum moment coefficients increase with increasing axial load. To study the influence of taper, plastic resistance and end conditions on the flexural behaviour of the pile, Table 1 is prepared from the Figs. 3 to 6 for $A_{Q}=0.75$ and $U=0.1 U_{c r}$. The top deflection coefficients increase with taper considerably in the case of free-free pile and to a lesser extent in the case of fixed-free pile. Also, for the same loads, the deflection of the fixed-free pile is considerably less than that in the case of free-free pile. This shows the overwhelming influence of end conditions on pile deflection. The maximum $A_{M}$ values increase with taper, but only very marginally. The $A_{y o}$ and maximum $A_{M}$ for $W=0.5$ are less compared to the values for $W=0.25$.

Table 1. Top deflection coefficients and maximum moment coefficients for $A_{Q}=0.75$ and $U=0.1 U_{c r}$

\begin{tabular}{l|c|c|c|c|c|c|c|c}
\hline \multirow{3}{*}{$C$} & \multicolumn{3}{|c|}{ Free-free pile $\begin{array}{c}A_{Q}=0.75 \\
U=0.1 U_{c r}\end{array}$} & \multicolumn{3}{c}{ Fixed-free pile $A_{Q}=0.75$} \\
$U=0.1 U_{c r}$
\end{tabular}

A numerical example is worked out in Appendix to illustrate the use of the results presented.

\section{CONCLUSIONS}

The analysis presented here may be used to make realistic estimate of the pile deflection and maximum moment, as the variation of flexural rigidity along the length of pile, the yielding of soil near the ground surface, the axial load and the end conditions which have considerable influence on the flexural behaviour of the pile are taken into account. The results presented show that the top deflections and maximum moments increase with increasing axial load and taper. For given axial and lateral loads, the top deflection in the case of fixed-free pile is considerably less than that in the case of free-free pile.

\section{ACKNOWLEDGEMENT}

The financial assistance given by the Council of Scientific and Industrial Research (India) is gratefully acknowledged.

\section{NOTATION}

$A=$ coefficient which depends on the relative density of sand $a_{0}, a_{1}, a_{2}, a_{3}=$ constants

$A_{M}=$ non-dimensional moment coefficient

$A_{Q}=$ non-dimensional lateral load factor

$A_{y}=$ non-dimensional deflection coefficient 
$A_{y 0}=$ top deflection coefficient

$B=$ width of the pile

$b=\frac{C-1}{L}$

$C=$ ratio of the bottom diameter to the top diameter of the pile

$C_{0} C_{1}, C_{2}, C_{3},=$ constants

$D_{0}=$ top diameter of the pile

$d^{\prime}=(C-1) / z^{\prime}$

$E=$ Young's modulus of elasticity of the pile material

$I_{0}=$ moment of inertia of the pile cross-section at top

$I(x)=$ moment of inertia of the pile cross-section at depth $x$ from the top

$k_{0}=$ coefficient of earth pressure at rest

$k=$ constant of horizontal subgrade reaction

$k_{2}, k_{3}=$ non-dimensional coefficients

$L=$ length of the pile

$M=$ bending moment

$P=$ axial load acting at the top of the pile

$P(x)=$ axial load acting at depth $x$ from the top of the pile

$p_{u t t}=$ ultimate soil resistance per unit length of the pile

$Q=$ lateral load

$R=$ relative stiffness factor

$t_{1}, t_{2}=$ coefficients of ultimate soil resistance

$U=$ non-dimensional axial load factor

$U_{c r}=$ non-dimensional buckling load

$v=\ln \left(1+d^{\prime} z\right)$

$W=$ non-dimensional plastic resistance coefficient

$x=$ depth from ground level

$x_{1}=$ depth of plastic zone

$y=$ deflection of the pile

$z=$ depth coefficient

$z^{\prime}=$ maximum depth coefficient

$z_{1}=$ non-dimensional depth of plastic zone

$\alpha_{1}, \alpha_{2}, \alpha_{3}, \alpha_{4}=$ roots

$\gamma=$ unit weight of soil

$\eta=\frac{U}{d^{\prime 2}}$

$\lambda_{1}, \lambda_{2}, \lambda_{3}, \lambda_{4}=$ coefficients defined by Eqs. (25), (26), (27) and (34)

$\phi=$ angle of internal friction of the soil

$\theta=$ angle made by the plane cdef of the shearing wedge of soil with the vertical

\section{REFERENCES}

1) Broms, B. B. (1964): "Lateral resistance of piles in cohesionless soils," Journal of the Soil Mechanics and Foundations Division, ASCE, Vol. 90, No. SM3, Proc. paper 3909, pp. 123-156.

2) Kananyan, A. S. (1968): “Analysis of horizontally loaded piles," Translated from Osnovaniya, Fundamenty $i$ Mekhanika Gruntov, No. 2, March-April, pp. 10-14.

3) Reese, L. C. (1958): Discussion on "Soil modulus for laterally loaded piles," by B. McClelland and Focht, J. A., Transactions, ASCE, Vol. 123.

4) Siva Reddy, A. and Valsangkar, A. J. (1970): "Generalized solutions for laterally loaded pile in 
elasto-plastic soil," Soils and Foundations, Vol. 10, No. 3, pp. 66-80.

5) Terzaghi, K. (1955): "Evaluation of coefficient of subgrade reaction," Geotechnique, The Institution of Engineers, London, Vol. 5, pp. 297-326.

6) Valsangkar, A. J. (1969): "Flexural and buckling behaviour of individual piles and two-dimensional analysis of group of piles," The thesis submitted to Indian Institute of Science, Bangalore, for the degree of Doctor of Philosophy.

7) Van Leyden, W. (1971): "Plastic-elastic analysis of laterally loaded free-standing piles," de ingeneieur, Jaargang 83 , No. 23, A 391-404, B 101-112, E 65-74.

\section{APPENDIX}

A reinforced concrete pile with top diameter $0.30 \mathrm{~m}$ and uniformly tapering to $0.20 \mathrm{~m}$ at the bottom is driven in a sand deposit. The axial load acting at top of the pile, $P=50 t$. The pile and soil date are: $L=10 \mathrm{~m}, E$ of concrete $=2,650,000 t / \mathrm{m}^{2}, I_{0}=0.00046 \mathrm{~m}^{4}$, $\gamma=1.8 \mathrm{t} / \mathrm{m}^{3}, \phi=25^{\circ}, k=400 t / \mathrm{m}^{3}$. It is required to calculate the top deflections and maximum moments for different lateral loads.

\section{Solution}

$$
\begin{aligned}
R=\sqrt[5]{\frac{E I_{0}}{k}} & =\sqrt[5]{\frac{2,650,000 \times 0.00046}{400}} \\
& =1.25 \mathrm{~m} \\
z^{\prime}=\frac{L}{R}= & \frac{10}{1.25}=8>4
\end{aligned}
$$

The results presented for $z^{\prime}=4$ can be used. The value of $C$ should be taken as the ratio of the pile diameter at $z=4$ to the pile diameter at top. The diameter of the pile at $z=4$ below ground level $=0.25 \mathrm{~m}$.

$$
C=\frac{0.25}{0.30}=0.833
$$

\section{Determination of $t_{1}$ and $t_{2}$}

For $\phi=25^{\circ}, \theta=39.5^{\circ}$ (Kananyan, 1968)

$$
\begin{aligned}
t_{1} & =r B \tan \theta \cot (\theta-\phi) \\
& =1.8 \times 0.3 \times 0.8243 \times 3.865 \\
& =1.72 t / m^{2} . \\
t_{2} & =\{\sin \theta+\cos \theta \cot (\theta-\phi)\} k_{0 \gamma} \tan \theta \tan \phi+\gamma \tan ^{2} \theta \tan \phi \cot (\theta-\phi)
\end{aligned}
$$

Assuming $k_{0}=0.5$,

$$
\begin{aligned}
t_{2} & =(0.6361+0.7716 \times 3.865) 0.5 \times 1.8 \times 0.8243 \times 0.4663+1.8 \times 0.8243^{2} \times 0.4663 \times 3.865 \\
& =3.46 \mathrm{t} / \mathrm{m}^{3} . \\
W & =\frac{t_{1}}{t_{2} R}=\frac{1.72}{3.46 \times 1.25}=0.398 \\
U & =\frac{P R^{2}}{E I_{0}}=\frac{50 \times 1.25^{2}}{2,650,000 \times 0.00046}=0.0642 \text { (or) } 0.07 U_{c r} .
\end{aligned}
$$

Using the Figs. 3 to $6, A_{Q}$ vs $A_{y 0}$ and $A_{Q}$ vs Max. $A_{M}$ relationships for $U=0.07 U_{c r}$, $C=0.833$ and $W=0.398$ are obtained by linear interpolation. For example from Fig. 3a, by interpolating the plots corresponding to $U=0.05 U_{c r}$ and $0.1 U_{c r}$ given for $C=1.0, A_{\ell}$ vs $A_{y 0}$ plot for $U=0.07 U_{\text {or }}$ is obtained. Similarly, another $A_{Q}$ vs $A_{y 0}$ plot for $U=0.07 U_{c r}$ is obtained from the plots given for $C=0.75$. Again interpolating these two plots, the one corresponding to $C=0.833$ is obtained. Thus, $A_{Q}$ vs $A_{y 0}$ plot for $U=0.07 U_{c r}, C=$ 
0.833 and $W=0.25$ is obtained from Fig. 3a. Adopting the same procedure, another $A_{Q}$ vs $A_{y 0}$ plot for $U=0.07 U_{c r}, C=0.833$ and $W=0.5$ is obtained from Fig. $3 \mathrm{~b}$. Finally, the above two plots are interpolated to get the $A_{Q}$ vs $A_{y 0}$ relationship for $U=0.07 U_{c r}$, $C=0.833$ and $W=0.398$. The same approach is adopted to obtain the $A_{Q}$ vs Max. $A_{M}$ relationship. The non-dimensional values of $A_{Q}$ and the corresponding $A_{y 0}$ and Max. $A_{M r}$ thus obtained are converted to dimensional form using the Eqs. (53), (14) and (15) respectively. The results are presented in Fig. 7.

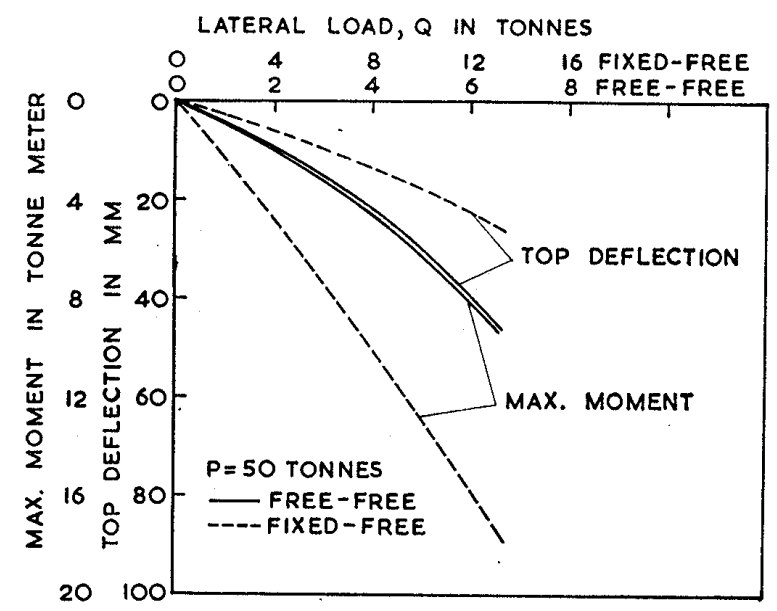

Fig. 7. Lateral load vs. top deflection and Max. moment for free-free and fixed-free piles

(Received November 21, 1972) 